\title{
Analisis Efektivitas Program Promosi IMOVSES terhadap Tingkat Penggunaan Produk Microsoft Berlisensi pada Sivitas IPB
}

\author{
Ifan Harnata Sembiring \\ Departemen Manajemen, Fakultas Ekonomi dan Manajemen \\ Institut Pertanian Bogor \\ Kampus Dramaga Bogor 16680 \\ Jono M Munandar \\ Departemen Manajemen, Fakultas Ekonomi dan Manajemen \\ Institut Pertanian Bogor \\ Kampus Dramaga Bogor 16680 \\ e-mail: jonomun@gmail.com
}

\begin{abstract}
Bogor Agricultural University (IPB) Microsoft Open Value Subcscription for Education Solution or IMOVSES is a Microsoft promotion program managed by Directorate of Integration of Data and Information Systems of IPB in order to introduce and increase the use of Microsoft licensed products to IPB academicians by offering Microsoft licensed products with significant discount. The purposes of this study are to identify the characteristics of IPB academicians upon licensed software usage decisions, and to analyze both responses to the IMOVSES promotion and effectiveness of budgeting program IMOVSES promotion. The method used to identify the characteristics of IPB academicians is chi square, while EPIC Model and Direct Rating Method are used to analyze the responses of the academicians, and regression analysis is used to analyze the effectiveness of promotion budgeting. The result of EPIC Rate is equal to 3.15 , which indicates that the promotion is in the range of reasonably effective. Direct value rating (ğ) obtained was 64.14, which shows that the promotion is included in either category. Regression equations obtained is "Total academicians $=27.2+0.000027$ promotion fee" which shows that if the cost of the promotion was added by Rp100,000,-, it will increase the number of academicians by 3 people. Finally, It requires at least $R p 127,300,000$,- to make this promotion program effective.
\end{abstract}

Keywords: academicians, effectiveness, licensed products, promotion, software

\begin{abstract}
ABSTRAK
Institut Pertanian Bogor (IPB) Microsoft Open Value Subcscription for Education Solution atau IMOVSES merupakan program promosi Microsoft yang dikelola oleh IPB dalam rangka memperkenalkan sekaligus meningkatkan penggunaan produk Microsoft berlisensi kepada sivitas akademika IPB dengan cara menawarkan produk Microsoft berlisensi dengan potongan harga yang signifikan. Tujuan penelitian ini adalah untuk mengidentifikasi karakteristik sivitas IPB terkait keputusan penggunaan software berlisensi, menganalisis respon sivitas IPB terhadap program promosi IMOVSES, serta menganalisis efektivitas penganggaran biaya program promosi IMOVSES. Metode yang digunakan untuk mengidentifikasi karakteristik sivitas IPB adalah chi square, untuk menganalisis respon sivitas digunakan
\end{abstract}


EPIC Model dan Direct Rating Method, sedangkan untuk menganalisis efektivitas penganggaran promosi digunakan analisis regresi. EPIC Rate yang dihasilkan adalah sebesar 3,15, yang menunjukkan bahwa promosi berada pada rentang cukup efektif. Nilai direct rating (ğ) diperoleh sebesar 64,14, yang menunjukkan bahwa promosi masuk dalam kategori baik. Persamaan regresi yang diperoleh adalah "Jumlah sivitas $=27,2+0,000027$ Biaya promosi" yang menunjukan bahwa apabila biaya promosi ditambah sebesar Rp100.000,- akan menambah jumlah sivitas sebanyak 3 orang. Dibutuhkan setidaknya biaya sebesar Rp127.300.000,- untuk menjadikan program promosi efektif secara penjualan.

Kata kunci: efektivitas, produk berlisensi, promosi, sivitas, software

\section{Pendahuluan}

Institut Pertanian Bogor (IPB) merupakan lembaga pendidikan tinggi yang berkeinginan untuk menjadi universitas riset terkemuka di Asia dan menghasilkan lulusan yang mampu berkontribusi pada kemajuan ilmu pengetahuan, teknologi, dan seni (IPTEKS). IPB merintis dan mengembangkan model pembelajaran berbasis sistem informasi dan teknologi untuk mendukung sistem pendidikan konvensional yang sudah ada. Teknologi di bidang informasi memegang peranan penting dalam memajukan kehidupan (Utami 2011). Melalui teknologi informasi perusahaan dapat memperoleh keunggulan strategis dalam persaingan antar para pelaku bisnis. Kegiatan institusi dengan kebutuhan software komputer sangat erat hubungannya. Software komputer berperan dalam menunjang segala aktivitas pendidikan agar dapat berjalan lebih efisien. Software komputer adalah program-program yang mengatur kerja sistem komputer sehingga seluruh peralatan komputer menjadi terkontrol dan pekerjaan yang berkaitan dengan komputer lebih efisien (Suyanto 2005).

Microsoft Corporation merupakan salah satu perusahaan yang memproduksi software komputer dengan tingkat penggunaan yang tinggi. Produk Microsoft merupakan produk yang paling banyak digunakan oleh pengguna komputer di dunia, termasuk di Indonesia. Perkembangan perangkat lunak diikuti dengan tindak pelanggaran hak Kekayaan Intelektual yakni dalam bentuk pembajakan software yang belakangan ini semakin marak terjadi di Indonesia. Indonesia menempati posisi 11 peredaran software bajakan di dunia, software ilegal yang beredar dalam skala nasional adalah sekitar $86 \%$ mengakibatkan kerugian sekitar Rp12,8 triliun (International Data Corporation 2012).

Kesepakatan kerjasama antara IPB dan Microsoft yang tertuang dalam Campus Agreement, memungkinkan sivitas akademika IPB untuk dapat menggunakan produk Microsoft berlisensi dengan murah dan secara aspek legal IPB dapat terhindar dari tuntutan hukum. Produk yang telah diperbanyak antara lain Microsoft Windows 7, Windows 8, Microsoft Office 2010 dan Microsoft Office 2013, sivitas akademika IPB juga dapat melakukan pemesanan untuk software tertentu di Direktorat Integrasi Data dan Sistem Informasi IPB. Kerjasama ini dilaksanakan mengingat tingginya minat mahasiswa, dosen, dan unit kerja IPB terrhadap software Microsoft untuk menunjang aktivitas institusi yang berlangsung di lingkungan IPB. Kerjasama ini kemudian diharapkan mampu mengurangi peredaran perangkat lunak ilegal yang beredar dikalangan sivitas IPB.

Promosi merupakan salah satu dari empat elemen dasar marketing atau pemasaran, keempat elemen itu adalah product (produk), place (tempat), price (harga) dan promotion (promosi) (Ferinadewi 2005). IPB Microsoft Open Value Subcscription 
For Education Solution atau IMOVSES merupakan salah satu media promosi yang dimiliki oleh Microsoft. Perbedaan IMOVSES dengan promosi-promosi lainnya adalah dari segi audiens, konsep promosi, serta interaksi konsumen terhadap promosi, dimana Microsoft lebih menyasar segmentasi sivitas kampus dengan memberikan perangkat lunak berlisensi secara gratis.

Promosi yang dijalankan secara efektif dan dikendalikan dengan baik maka akan berperan dalam mempengaruhi dan menaikan minat konsumen yang pada akhirnya akan berpengaruh secara signifikan terhadap jumlah pembelian produk berlisensi. Anggaran yang sangat besar tidak menjamin keberhasilan dalam suatu kegiatan promosi (Arfianto 2010, Kodu 2013 dan Mongi et al. 2013). Proses pengambilan keputusan berawal dari pengenalan masalah, pencarian informasi, evaluasi alternatif produk, keputusan pembelian dan perilaku pasca pembelian. Pengenalan masalah dipicu oleh adanya keinginan dan kebutuhan konsumen. Kemudian dilanjutkan dengan proses pencarian informasi yang akan menghasilkan berbagai alternatif produk. Evaluasi alternatif dilakukan untuk mendapatkan produk yang sesuai. Keputusan pembelian dilakukan setelah melewati tiga tahap proses tersebut. Tingkat kepuasan pasca pembelian berpengaruh terhadap perilaku pasca pembelian (Kotler 2009), oleh karena itu, penelitian ini menyatakan perlunya mengkaji proses keputusan pembelian oleh konsumen terhadap penggunaan software berlisensi. Dengan demikian, tujuan diadakan penelitian ini adalah 1) mengidentifikasi karakteristik sivitas IPB terkait keputusan penggunaan software berlisensi; 2) menganalisis respon sivitas akademika IPB terhadap program promosi IMOVSES; 3) menganalisis efektivitas penganggaran biaya promosi IMOVSES.

\section{Metode Penelitian}

Promosi merupakan salah satu faktor penentu keberhasilan dalam pemasaran. Menurut Tjiptono (2005), tujuan utama dari promosi adalah menginformasikan, mempengaruhi dan membujuk, serta mengingatkan pelanggan sasaran tentang perusahaan dan bauran pemasarannya. Promosi berarti aktivitas yang menyampaikan manfaat produk dan membujuk pelanggan membelinya (Sukma 2011). Microsoft Corporation sebagai pemimpin pasar perangkat lunak komputer di Indonesia memahami bahwa dunia pendidikan harus senantiasa didukung oleh perangkat lunak komputer yang dapat terlepas dari dukungan perangkat lunak yang terbaru, aman, dan mudah didapatkan.

Microsoft menjalin kerjasama dengan Institut Pertanian Bogor (IPB) dalam bentuk IPB Microsoft Open Value Subcscription For Education Solution atau IMOVSES. Program Promosi ini diharapkan mampu meningkatkan penggunaan produk Microsoft berlisensi di kalangan sivitas akademika IPB. Program promosi ini dapat diukur efektivitasnya dengan memperhatikan kriteria promosi yang efektif menurut Engel (1994), yaitu pasar sasaran yang diharapkan, komunikasi yang diharapkan, dan hasil penjualan yang diharapkan.

Penelitian dilaksanakan pada bulan September-November 2014. Penelitian dilaksanakan di kampus Institut Pertanian Bogor. Waktu penelitian dimulai dari pukul 08.00 s.d. 15.00 WIB. Metode sampling yang digunakan adalah purposive sampling. 
Teknik purposive sampling dipilih karena adanya kriteria tertentu (Singarimbun dan Effendi, 1995). Penulis mengambil beberapa sivitas yang mengetahui program IMOVSES dan menggunakan produk Microsoft baik yang berlisensi maupun yang tidak berlisensi. Jenis data yang digunakan adalah data primer dan sekunder. Data primer tersebut merupakan data yang diperoleh melalui kuesioner yang dibagikan secara langsung kepada sivitas akademika IPB. Data sekunder terdiri dari laporan biaya dan jumlah peminat program promosi IMOVSES, bahan pustaka, jurnal, penelitian terdahulu, buku-buku serta literatur lain yang terkait dengan penelitian ini.

Efektifitas adalah suatu ukuran yang menyatakan seberapa jauh target (kuantitas, kualitas dan waktu) yang telah dicapai oleh manajemen, yang mana target tersebut sudah ditentukan terlebih dahulu (Patimeh 2010). Data yang telah terkumpul kemudian dianalisis dengan menggunakan analisis Chi Square untuk mengidentifikasi karakteristik responden (sivitas) dan pasar sasaran yang diharapkan. Efektivitas promosi dianalisis dengan menggunakan metode EPIC Model dan Direct Rating Method (DRM) sementara Metode yang digunakan untuk menganalisis efektivitas penganggaran biaya adalah analisis regresi. Kerangka pemikiran pada penelitian ini terdapat pada Gambar 1.

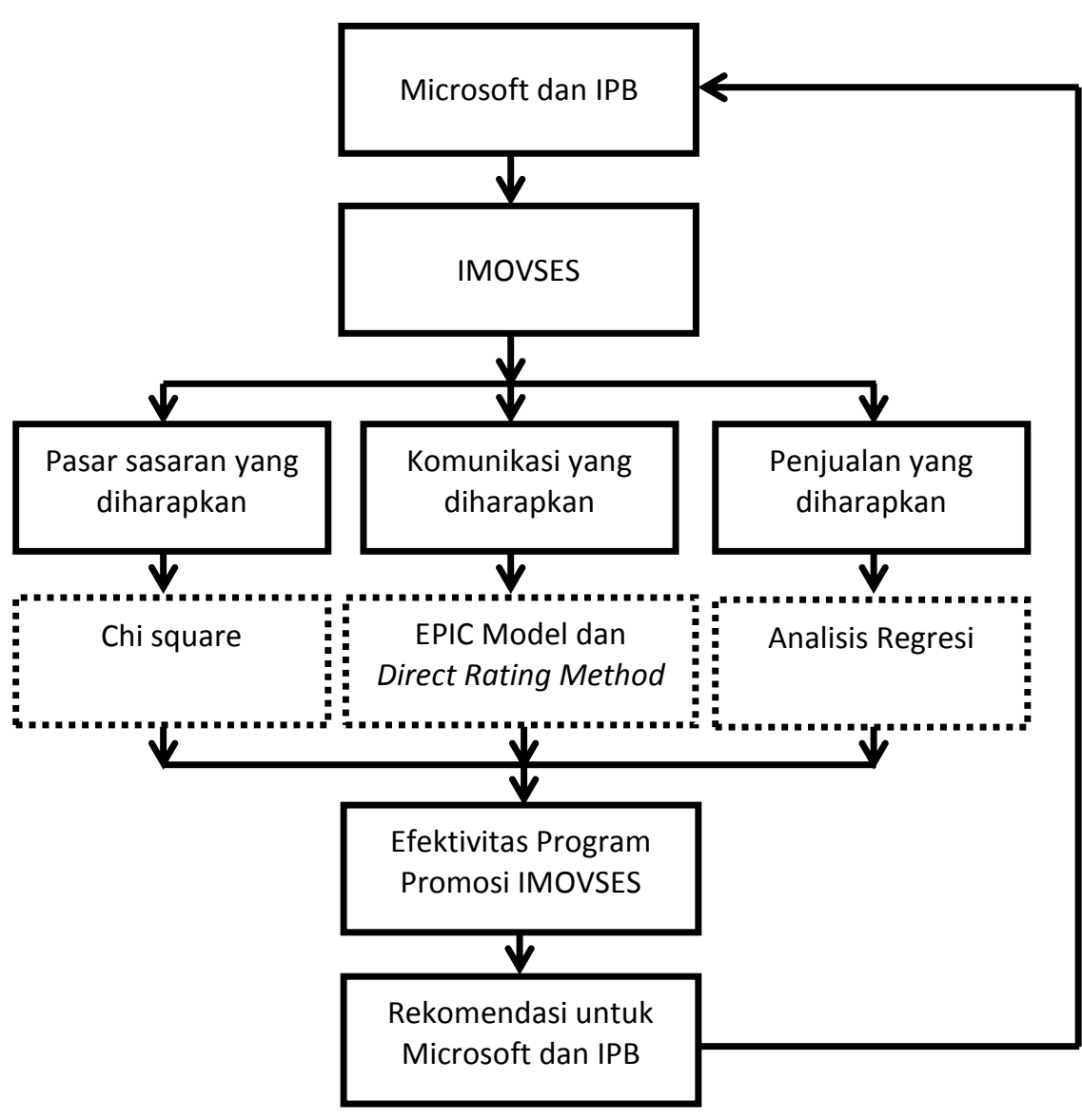

Gambar 1. Kerangka pemikiran

Penulis mengambil beberapa sivitas yang mengetahui program IMOVSES dan menggunakan produk Microsoft baik yang berlisensi maupun yang tidak berlisensi. 
Jumlah sampel ditentukan dengan merujuk kepada rumus Slovin yang digunakan untuk menentukan ukuran minimal sampel yang dibutuhkan dari suatu populasi sehingga dapat menggambarkan serta mewakili data populasi. Adapun rumus Slovin dalam Umar (2005) adalah sebagai berikut:

$$
\mathrm{n}=\frac{\mathrm{N}}{1+\mathrm{N}(\mathrm{e})^{2}}
$$

di mana:

$\mathrm{n}=$ jumlah sampel

$\mathrm{N}=$ jumlah populasi

e $=$ taraf nyata (batas toleransi kesalahan) $10 \%$

Definisi operasional variabel yang dianalisis dengan menggunakan metode DRM meliputi :

1. Perhatian. Faktor Perhatian digunakan untuk mengetahui seberapa besar alokasi kapasitas untuk stimulus yang masuk dan diproses oleh sivitas IPB yang berminat mengikuti program promosi IMOVSES.

2. Pemahaman. Pemahaman digunakan untuk mengetahui seberapa baik penafsiran suatu stimulus promosi yang diterima oleh sivitas IPB.

3. Respon kognitif. Respon kognitif digunakan untuk mengetahui penerimaan yang terkait dengan pikiran yang muncul selama tahap pemahaman promosi.

4. Respon afektif. Respon afektif menggambarkan perasaan dan emosi sivitas IPB yang dihasilkan sebuah stimulus (dalam hal ini adalah pesan promosi).

5. Sikap terhadap promosi. Respon konsumen terhadap promosi yang diberikan oleh Microsoft, dan ini bisa digunakan untuk memprediksikan perilaku setuju atau tidaknya konsumen terhadap manfaat software berlisensi.

Definisi operasional variabel yang dianalisis dengan menggunakan metode EPIC meliputi :

1. Empati (Empathy)

Dimensi Empati digunakan untuk mengetahui pendapat sivitas mengenai strategi promosi yang dilakukan Direktorat Integrasi Data dan Sistem Informasi IPB.

2. Persuasi (Persuasion)

Persuasi dapat didefenisikan sebagai perubahan kepercayaaan, sikap, dan juga keinginan untuk berperilaku yang disebabkan oleh suatu komunikasi promosi.

3. Dampak (Impact)

Dimensi impact menunjukkan apakah suatu promosi terlihat istimewa atau menonjol dibandingkan promosi lainnya pada kategori serupa dan apakah suatu promosi dapat membuat konsumen terlibat dalam pesan yang disampaikan.

4. Komunikasi (Communication)

Dimensi communication mengindikasikan apakah konsumen mengingat pesan utama yang disampaikan, apakah konsumen memahaminya, dan apakah pesan tersebut memiliki kesan atau kekuatan yang ditinggalkan pada konsumen. 


\section{Hasil dan Pembahasan}

III.1. Profil Institut Pertanian Bogor

Institut Pertanian Bogor (IPB) merupakan lembaga pendidikan tinggi sebagai kelanjutan dari lembaga pendidikan menengah dan tinggi pertanian serta kedokteran hewan yang dimulai pada awal abad ke-20 di Bogor. Pada tahun 1947 dibuka Faculteit voor Landbouw Hogeschool sebagai lanjutan Landbouw Hogeschool yang didirikan pemerintah Hindia Belanda pada tahun 1940. Faculteit voor Landbouw Hogeschool mempunyai jurusan pertanian dan kehutanan. Kedua jurusan tersebut bernaung di bawah Universiteit van Indonesie yang kemudian berubah nama menjadi Universitas Indonesia (UI). Pada tanggal 1 September 1963, berdasarkan Keputusan Menteri Pendidikan Tinggi dan Ilmu Pengetahuan (PTIP) Nomor 91 tahun 1963, Fakultas Pertanian, Fakultas Kedokteran Hewan, Fakultas Peternakan UI melepaskan diri menjadi Institut Pertanian Bogor dan disahkan oleh presiden RI dengan keputusan No. 2791 Tahun 1965.

Pada tanggal 26 Desember 2000 melalui Peraturan Pemerintah No.154 IPB telah ditetapkan sebagai Badan Hukum Milik Negara (BHMN). Dengan penetapan ini, maka IPB dalam menyelenggarakan kegiatan tridharma sudah bersifat otonom. Guna menghadapi era globalisasi, IPB telah mencanangkan konsep Pembangunan Pertanian Berkebudayaan Industri (PPBI) yang diharapkan dapat menjadikan Indonesia sebagai negara berbasis pertanian yang tangguh. Disamping itu sesuai dengan visi 2025 IPB di mana IPB adalah perguruan tinggi bertaraf internasional dalam pengembangan sumberdaya manusia dan IPTEKS dengan kompetensi utama di bidang pertanian.

Direktorat Komunikasi dan Informasi adalah salah satu unsur pelaksana administrasi IPB. Direktorat ini memiliki berbagai program antara lain Authorized Testing Center (ATC) yaitu program promosi sertifikasi Microsoft di mana sivitas IPB memperoleh potongan biaya hingga 30\% lebih murah, Cyber Mahasiswa, IMOVSES (Lisensi Microsoft) yang memungkinkan sivitas IPB memperoleh potongan harga signifikan atas produk-produk Microsoft, Blog Staff IPB, Jurnal IImiah IPB, Layanan Email, Akses Pengguna, IPBnet Lokasi Hotspot, Video Conference, Download File, VolP IPB, Green TV.

\section{III.2. Kakteristik Responden}

Karakteristik responden dalam penelitian ini dapat dilihat dari jenis kelamin, usia, fakultas, status sivitas, sumber pemasukan, jumlah pemasukan per bulan, serta hobi. Karakteristik responden berdasarkan kategorinya dapat dilihat pada Tabel 1.

Tabel 1. Karakteristik responden berdasarkan kategori

\begin{tabular}{|c|c|c|}
\hline Kategori & Karakteristik & Persentase(\%) \\
\hline \multirow{2}{*}{ Jenis Kelamin } & Pria & 68 \\
\hline & Wanita & 32 \\
\hline \multirow{5}{*}{ Usia } & $\leq 20$ tahun & 22 \\
\hline & 21-30 tahun & 69 \\
\hline & 31-40 tahun & 1 \\
\hline & $41-50$ tahun & 4 \\
\hline & $>50$ tahun & 4 \\
\hline
\end{tabular}


Lanjutan Tabel 1.

\begin{tabular}{lll}
\hline \multicolumn{1}{c}{ Kategori } & \multicolumn{1}{c}{ Karakteristik } & Persentase(\%) \\
\hline \multirow{3}{*}{ Status Sivitas } & Mahasiswa & 91 \\
& Tenaga Kependidikan & 5 \\
& Tenaga Pengajar & 1 \\
& Administrator & 3 \\
\hline \multirow{3}{*}{ Sumber Pemasukan Utama } & Uang saku dari orang tua & 81 \\
& Gaji & 14 \\
& Beasiswa & 5 \\
\hline \multirow{3}{*}{ Jumlah Pemasukan Per Bulan } & $<$ Rp1.000.000,- & 2 \\
& Rp1.000.000,- - Rp1.999.000,- & 48 \\
& Rp2.000.000,- - Rp2.999.000,- & 34 \\
& Rp3.000.000,- - Rp3.999.000,- & 6 \\
& Rp4.000.000,- - Rp4.999.000,- & 2 \\
& $>$ Rp5.000.000,- & 8 \\
\hline & Membaca & 13 \\
Hobi & Musik & 11 \\
& Menonton film & 30 \\
& Desain/ Photograpi & 3 \\
& Komputer & 13 \\
& Traveling & 10 \\
& Olahraga & 20 \\
\hline
\end{tabular}

Responden memiliki karakteristik yang lebih spesifik mengenai poduk Microsoft dan program promosi IMOVSES yaitu mengenai keikutsertaan dalam seminar software berlisensi, wawasan mengenai software berlisensi, penggunaan produk Microsoft, produk Microsoft yang terakhir dibeli, keaslian software, sumber produk, durasi menggunakan komputer, keperluan menggunakan komputer, dan sumber informasi mengenai IMOVSES. Karakteristik responden mengenai Microsoft dan IMOVSES berdasarkan kategorinya dapat dilihat pada Tabel 2.

Tabel 2. Karakteristik responden mengenai Microsoft berdasarkan kategori

\begin{tabular}{|c|c|c|}
\hline Kategori & Karakteristik & Persentase(\%) \\
\hline \multirow{2}{*}{$\begin{array}{l}\text { Mengikuti } \\
\text { Seminar }\end{array}$} & Pernah & 36 \\
\hline & Tidak pernah & 64 \\
\hline \multirow{3}{*}{$\begin{array}{l}\text { Wawasan } \\
\text { Mengenai } \\
\text { Software } \\
\text { Berlisensi }\end{array}$} & Baik & 24 \\
\hline & Cukup & 53 \\
\hline & Tidak paham/ buruk & 23 \\
\hline \multirow{2}{*}{$\begin{array}{l}\text { Pengguna } \\
\text { Produk } \\
\text { Microsoft }\end{array}$} & Ya & 96 \\
\hline & Kombinasi & 4 \\
\hline \multirow{6}{*}{$\begin{array}{l}\text { Produk } \\
\text { Microsoft } \\
\text { terakhir yang } \\
\text { dibeli }\end{array}$} & Microsoft Office & 59 \\
\hline & Microsoft Visio & 5 \\
\hline & Windows Vista & 1 \\
\hline & Windows XP & 8 \\
\hline & Windows 7 & 15 \\
\hline & Windows 8 & 12 \\
\hline
\end{tabular}


Lanjutan Tabel 2.

\begin{tabular}{|c|c|c|}
\hline Kategori & Karakteristik & Persentase(\%) \\
\hline \multirow{12}{*}{$\begin{array}{l}\text { Mulai } \\
\text { menggunakan } \\
\text { produk } \\
\text { Microsoft }\end{array}$} & $<2004$ & 5 \\
\hline & 2004 & 3 \\
\hline & 2005 & 2 \\
\hline & 2006 & 7 \\
\hline & 2007 & 22 \\
\hline & 2008 & 18 \\
\hline & 2009 & 20 \\
\hline & 2010 & 15 \\
\hline & 2011 & 5 \\
\hline & 2012 & 2 \\
\hline & 2013 & 0 \\
\hline & 2014 & 1 \\
\hline $\begin{array}{l}\text { Menggunakan } \\
\text { Produk }\end{array}$ & Berlisensi (asli) & 27 \\
\hline $\begin{array}{l}\text { Microsoft } \\
\text { Berlisensi }\end{array}$ & Non lisensi & 73 \\
\hline \multirow{5}{*}{ Sumber produk } & Diberikan oleh teman & 53 \\
\hline & Diberikan oleh orang tua & 1 \\
\hline & Program IMOVSES & 25 \\
\hline & Membeli sendiri & 20 \\
\hline & Lainnya & 1 \\
\hline \multirow{5}{*}{$\begin{array}{l}\text { Lama } \\
\text { Menggunakan } \\
\text { Komputer (Per } \\
\text { hari) }\end{array}$} & $<1 \mathrm{Jam}$ & 1 \\
\hline & 1- 2 Jam & 50 \\
\hline & 2-3 Jam & 34 \\
\hline & 3-4 Jam & 10 \\
\hline & Di atas 4 Jam & 5 \\
\hline \multirow{4}{*}{$\begin{array}{l}\text { Keperluan } \\
\text { Menggunakan } \\
\text { Komputer }\end{array}$} & Desain/video editing/Game & 16 \\
\hline & Musik/Film & 15 \\
\hline & Pekerjaan/kuliah & 40 \\
\hline & Internet & 29 \\
\hline \multirow{7}{*}{$\begin{array}{l}\text { Informasi } \\
\text { mengenai } \\
\text { IMOVSES }\end{array}$} & Dari acara yang diadakan Microsoft & 3 \\
\hline & Dari Website & 15 \\
\hline & Informasi dari teman & 42 \\
\hline & Dari promosi tertentu di kampus & 10 \\
\hline & Dari acara yang diadakan IPB & 14 \\
\hline & Inisiatif menanyakan langsung & 3 \\
\hline & Ditawarkan petugas IMOVSES & 9 \\
\hline
\end{tabular}

Hubungan antara karakteristik responden dengan keputusan menggunakan produk Microsoft berlisensi dapat dianalisis dengan menggunakan analisis tabulasi silang atau crosstab. Melalui analisis tabulasi silang dapat diperoleh bagaimana suatu variabel bergantung atau tidak dengan variabel lainnya. Analisis tabulasi silang dilakukan dengan bantuan software SPSS 19. Adapun hubungan antar variabel yang akan dianalisis dapat dilihat pada Tabel 3. 
Tabel 3. Hubungan karakteristik responden dengan penggunaan software berlisensi

\begin{tabular}{|c|c|c|c|c|c|c|}
\hline Variabel & A & Df & $x^{2}$ tabel & $x^{2}$ hitung & Probabilitas & Keterangan \\
\hline $\begin{array}{l}\text { Usia-Penggunaan } \\
\text { Software Berlisensi }\end{array}$ & $\begin{array}{c}5 \% \\
(0,05)\end{array}$ & 4 & 9,488 & 13,031 & 0,017 & $\begin{array}{c}\text { Ada } \\
\text { Hubungan }\end{array}$ \\
\hline $\begin{array}{l}\text { Status Sivitas - } \\
\text { Penggunaan Software } \\
\text { Berlisensi }\end{array}$ & $\begin{array}{c}5 \% \\
(0,05)\end{array}$ & 3 & 7,813 & 10,601 & 0,023 & $\begin{array}{c}\text { Ada } \\
\text { Hubungan }\end{array}$ \\
\hline $\begin{array}{l}\text { Sumber Pemasukan - } \\
\text { Penggunaan Software } \\
\text { Berlisensi }\end{array}$ & $\begin{array}{c}5 \% \\
(0,05)\end{array}$ & 2 & 5,991 & 12,462 & 0,004 & $\begin{array}{c}\text { Ada } \\
\text { Hubungan }\end{array}$ \\
\hline $\begin{array}{l}\text { Jumlah Pendapatan - } \\
\text { Penggunaan Software } \\
\text { Berlisensi }\end{array}$ & $\begin{array}{c}5 \% \\
(0,05)\end{array}$ & 12 & 21,026 & 118,749 & 0,006 & $\begin{array}{c}\text { Ada } \\
\text { Hubungan }\end{array}$ \\
\hline $\begin{array}{l}\text { Mengikuti Seminar - } \\
\text { Penggunaan Software } \\
\text { Berlisensi }\end{array}$ & $\begin{array}{c}5 \% \\
(0,05)\end{array}$ & 1 & 3,841 & 51,414 & 0,000 & $\begin{array}{c}\text { Ada } \\
\text { Hubungan }\end{array}$ \\
\hline $\begin{array}{l}\text { Wawasan - } \\
\text { Penggunaan Software } \\
\text { Berlisensi }\end{array}$ & $\begin{array}{c}5 \% \\
(0,05)\end{array}$ & 2 & 5,991 & 21,502 & 0,000 & $\begin{array}{c}\text { Ada } \\
\text { Hubungan }\end{array}$ \\
\hline $\begin{array}{l}\text { Durasi Menggunakan } \\
\text { Komputer per Hari - } \\
\text { Penggunaan Software } \\
\text { Berlisensi }\end{array}$ & $\begin{array}{c}5 \% \\
(0,05)\end{array}$ & 4 & 9,488 & 6,754 & 0,149 & $\begin{array}{c}\text { Tidak } \\
\text { Berhubungan }\end{array}$ \\
\hline
\end{tabular}

Beberapa hal yang dapat dijadikan pertimbangan dalam menetapkan sasaran promosi ke depannya adalah variabel-variabel yang memiliki keterkaitan satu sama lainnya. Usia sivitas dan status sivitas mempengaruhi keputusannya dalam memilih menggunakan software berlisensi. Keputusan menggunakan software berlisensi memerlukan perilaku dan kemampuan pengguna untuk suka belajar banyak hal yang baru dan menyukai perubahan, dimana rentang usia yang diwakili merupakan rentang usia yang produktif dan lebih mampu beradaptasi dengan teknologi baru (Rajab 2009). Sumber pemasukan dan jumlah pemasukan adalah variabel lain yang memiliki pengaruh terhadap keputusan menggunakan software berlisensi. Secara umum sumber pemasukan sivitas IPB yang kebanyakan mahasiswa adalah uang saku dari orang tua dengan jumlah pemasukan mayoritas pada rentang Rp1.000.000,- hingga Rp2.000.000,- sehingga hal ini mempengaruhi daya beli terhadap produk-produk Microsoft berlisensi di luar kampus, maka sebenarnya IMOVSES adalah pilihan paling realistis untuk sivitas IPB. Hal ini yang harus ditekankan pada saat pertama kali mengadakan sosialisasi pada sivitas IPB.

Mengikuti seminar dan wawasan sivitas adalah variabel yang memiliki hubungan dengan keputusan penggunaan software berlisensi. Seminar adalah sarana penambahan pengetahuan mengenai software berlisensi sehingga sivitas semakin mengerti mengenai manfaat menggunakan produk Microsoft berlisensi.

Wawasan sivitas berpengaruh terhadap keputusan menggunakan produk Microsoft berlisensi. Sivitas dengan wawasan mengenai software berlisensi lebih mengerti mengenai manfaat menggunakan produk berlisensi serta konsekuensi menggunakan produk yang tidak berlisensi. Durasi seorang sivitas dalam menggunakan komputer setiap harinya tidak memiliki korelasi terhadap keputusannya menggunakan 
produk berlisensi atau tidak. Karakteristik Durasi menggunakan komputer tidak menentukan preferensi dalam pemilihan produk Microsoft berlisensi.

\section{III.3. Analisis Respon Sivitas terhadap Program Promosi IMOVSES}

Respon sivitas IPB terhadap program promosi IMOVSES dianalisis dengan menggunakan EPIC Model dan Direct Rating Method (DRM). EPIC Model mencakup empat dimensi kritis yaitu empati, persuasi, dampak dan komunikasi.

1. Empati (Empathy)

Skor rataan dimensi empati yang dihasilkan adalah sebesar 3,14. Skor 3,14 berada pada rentang skala 2,6 sampai 3,4 yang menunjukkan bahwa kegiatan promosi IMOVSES cukup efektif jika dilihat dari segi empati.

2. Persuasi (Persuasion)

Skor rataan dimensi persuasi yang dihasilkan adalah sebesar 3,965. Skor 3,965 berada pada rentang skala 3,4 sampai 34,2 yang menunjukkan bahwa kegiatan promosi IMOVSES adalah efektif jika dilihat dari segi persuasi.

3. Dampak (Impact)

Skor rataan dimensi dampak yang dihasilkan adalah sebesar 2,635. Skor 2,635 berada pada rentang skala 2,6 sampai 3,4 yang menunjukkan bahwa kegiatan promosi IMOVSES adalah cukup efektif jika dilihat dari segi dampak.

4. Komunikasi (Communication)

Skor rataan dimensi komunikasi yang dihasilkan adalah sebesar 2,893. Skor 2,893 berada pada rentang skala 2,6 sampai 3,4 yang menunjukkan bahwa kegiatan promosi IMOVSES adalah cukup efektif jika dilihat dari segi komunikasi.

\section{Nilai EPIC Rate}

Berdasarkan analisis yang dilakukan terhadap pengukuran efektivitas promosi IMOVSES dengan menggunakan EPIC Model, diketahui bahwa dimensi empati, dampak, dan komunikasi berada pada rentang cukup efektif, sementara dimensi persuasi berada pada rentang efektif. Rentang skala cukup efektif menunjukkan bahwa program promosi IMOVSES disukai oleh sivitas IPB dan sudah cukup memberi pengaruh terhadap sikap sivitas IPB terhadap minat penggunaan software Microsoft berlisensi. Program IMOVSES dinilai cukup menonjol dan menarik minat sivitas IPB, bahkan sivitas yang telah mengetahui program promosi IMOVSES telah benar-benar ingin untuk mulai menggunakan produk Microsoft melalui program promosi IMOVSES. Hal ini menunjukkan promosi IMOVSES memiliki kekuatan persuasi yang cukup kuat.

Skor rata-rata tiap dimensi dihitung kembali untuk menghasilkan EPIC Rate secara keseluruhan sehingga diperoleh nilai EPIC Rate sebesar 3,158. Nilai EPIC Rate 3,158 menunjukkan bahwa program promosi IMOVSES berada pada rentang skala cukup efektif. Oleh karena itu Direktorat Komunikasi dan Sistem Infromasi IPB harus lebih giat dalam melakukan promosi yang lebih sporadis agar menghasilnya tingkat penggunaan produk yang lebih tinggi lagi. Grafik hasil analisis efektivitas program promosi IMOVSES dapat dilihat pada Gambar 2. 


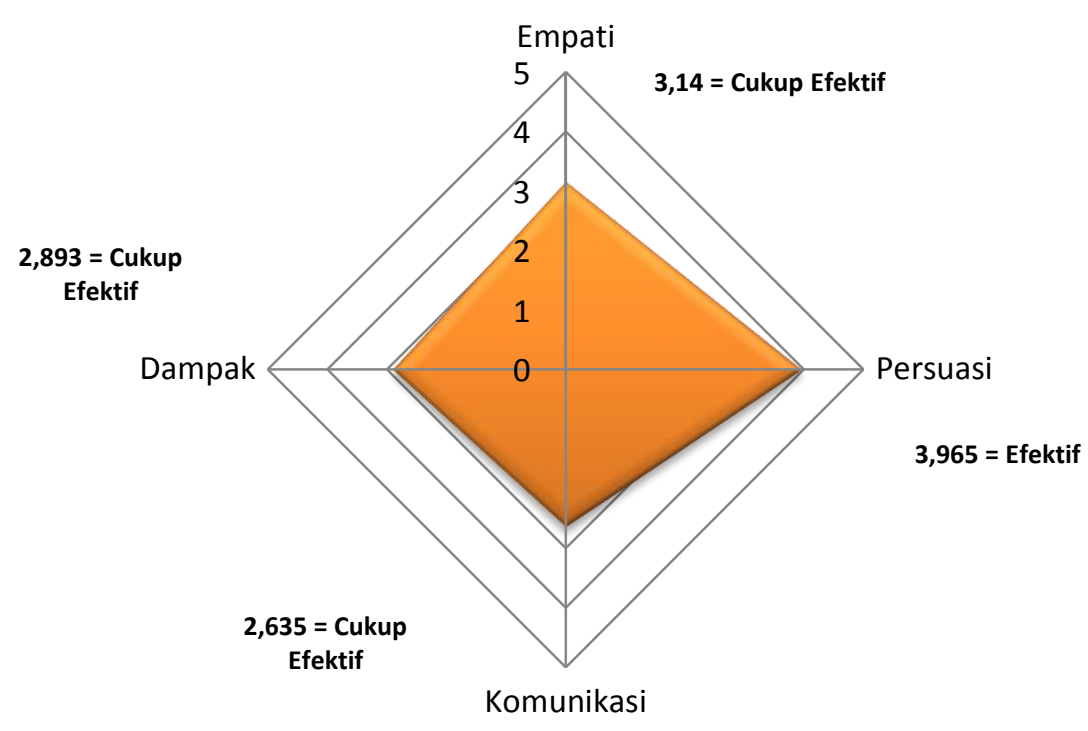

Gambar 2. EPIC Model program promosi IMOVSES

Direct Rating Method (DRM) menggunakan lima variabel, yaitu perhatian, pemahaman, respon kognitif, respon afektif, dan sikap terhadap promosi.

1. Perhatian

Skor rataan faktor perhatian yang dihasilkan adalah sebesar 3,155. Skor 3,115 berada pada rentang skala 2,6 sampai 3,4 yang menunjukkan bahwa kegiatan promosi IMOVSES adalah cukup efektif jika dilihat dari faktor perhatian.

2. Pemahaman

Skor rataan pemahaman yang dihasilkan adalah sebesar 3,08. Skor 3,08 berada pada rentang skala 2,6 sampai 3,4 yang menunjukkan bahwa kegiatan promosi IMOVSES adalah cukup efektif jika ditinjau dari pemahaman.

3. Respon Kognitif

Skor rataan respon kognitif yang dihasilkan adalah sebesar 2,79. Skor 2,79 berada pada rentang skala 2,6 sampai 3,4 yang menunjukkan bahwa kegiatan promosi IMOVSES adalah cukup efektif jika ditinjau dari repon kognitif.

4. Respon Afektif

Skor rataan respon afektif yang dihasilkan adalah sebesar 2,72. Skor 2,72 berada pada rentang skala 2,6 sampai 3,4 yang menunjukkan bahwa kegiatan promosi IMOVSES adalah cukup efektif jika ditinjau dari repon afektif.

5. Sikap Terhadap Promosi

Skor rataan faktor sikap responden yang dihasilkan adalah sebesar 4,29. Skor 4,29 berada pada rentang skala 4,2 sampai 5,0 yang menunjukkan bahwa kegiatan promosi IMOVSES adalah sangat efektif sekaligus menjadi skor tertinggi dari keempat faktor Direct Rating Method yang dianalisis.

\section{Nilai Total Direct Rating Method}

Setelah nilai total skor rataan diperoleh melalui masing-masing faktor yang kemudian dikonversi ke dalam skala tabel direct rating method, maka selanjutnya dilakukan penjumlahan seluruh faktor direct rating method. Hasil perhitungan skor direct rating method dapat dilihat pada Tabel 4. 
Tabel 4. Hasil perhitungan skor direct rating method

\begin{tabular}{lc} 
Faktor Direct Rating Method & $\begin{array}{c}\text { Skor hasil konversi ke skala tabel Direct } \\
\text { Rating Method }\end{array}$ \\
\hline Perhatian & 12,62 \\
Pemahaman & 12,32 \\
Respon Kognitif & 11,16 \\
Respon afektif & 10,88 \\
Sikap Terhadap Promosi & 17,16 \\
\hline Total Skor Direct Rating Method & $\mathbf{6 4 , 1 4}$ \\
\hline
\end{tabular}

Berdasarkan analisis dengan direct rating method yang ditunjukkan pada Tabel 4 , maka diperoleh nilai direct rating (ğ) sebesar 64,14 . Skor 64,14 berada pada skala 60 sampai dengan 80 yang berarti masuk dalam kategori baik. Walaupun masuk dalam kategori promosi yang baik, tetapi skor tersebut hanya berjarak 4 nilai dari kategori rata-rata. Hal ini membuktikan bahwa Direktorat Integrasi Data dan Sistem Informasi sebagai pengelola program promosi IMOVSES harus meningkatkan strategi pemasarannya lagi agar mendapat respon dari sivitas IPB dari aspek perhatian, pemahaman, respon kognitif, respon afektif, dan sikap terhadap promosi. Strategi pemasaran memandang kepuasan pelanggan sebagai fokus utama sehingga perusahaan akan selalu berusaha meningkatkan kualitas layanannya demi tercapainya tujuan tersebut (Ramdhan 2010 dan Verina et al. 2014).

III.4. Pengaruh Jumlah Biaya Promosi terhadap Penggunaan Produk Microsoft Berlisensi

Data yang diperoleh dari Laporan Tahunan Direktorat Integrasi Data dan Sistem Informasi IPB memuat jumlah anggaran yang dikeluarkan setiap tahunnya. Anggaran ini alokasikan per bulan setiap tahunnya dengan pertimbangan dari Subdit Integrasi Data IPB. Biaya promosi dianggarkan untuk sosialisasi, perbanyakan DVD, brosur, stiker, pelaksanaan acara atau seminar, penggantian perangkat komputer untuk proses perbanyakan DVD, dan lainnya.

Hubungan antara biaya promosi yang dikeluarkan dengan jumlah sivitas IPB yang menggunakan produk Microsoft berlisensi melalui IMOVSES dianalisis dengan menggunakan regresi linear dengan bantuan software Minitab 16. Lampiran 4 menunjukkan besarnya biaya promosi yang dikeluarkan Microsoft dan jumlah sivitas IPB yang menggunakan produk Microsoft berlisensi melalui program promosi IMOVSES.

Berdasarkan hasil analisis linear yang dilakukan dengan menggunakan software Minitab 16, diperoleh persamaan regresi sebagai berikut:

\section{Jumlah Sivitas $=27,2+0,000027$ Biaya Promosi}

Ada dua koefisien dalam persamaan regresi, yaitu koefisien $a$ dan $b$. Interpretasi dari koefisien $a$ adalah nilai y ketika $\mathrm{x}=0$. Intersep $(a)$ sebesar 27,2 secara matematis menyatakan bahwa apabila nilai Biaya sama dengan 0, maka nilai Sivitas(Y) sama dengan 27,2. Pada kasus ini tidak mungkin nilai biaya promosi sama dengan nol. Karena jika biaya sama dengan nol, maka program promosi IMOVSES sama saja tidak 
berjalan (IMOVSES adalah program promosi itu sendiri). Intersep pada hasil analisis ini bisa saja sivitas yang tetap menggunakan software adalah petugas pengelola IMOVSES sendiri.

Melalui persamaan regresi diinterpretasikan koefisien (b), yaitu jumlah sivitas yang mendaftar program promosi IMOVSES akan naik sebesar 0,000027 jika biaya dinaikkan sebesar satu satuan. Hal sebaliknya juga berlaku, jika biaya promosi dikurangi sebesar satu satuan biaya, maka program promosi IMOVSES akan kehilangan 0,000027 sivitas. Jadi, jika biaya promosi ditambah sebesar Rp100.000,- maka jumlah sivitas IPB yang akan mendaftar program promosi IMOVSES akan bertambah sebanyak 3 orang $(0,000027 \times \operatorname{Rp} 100.000,-)$.

Minitab juga menghasilkan ukuran seberapa baik peubah $x$ (peubah bebas) menjelaskan peubah y (peubah tidak bebas) dengan nilai $R^{2}$ sebesar $79,6 \%$ yang berarti biaya promosi yang dikeluarkan dapat menjelaskan tingkat sivitas yang mendaftar IMOVSES sebesar $79,6 \%$. Sisanya $20,4 \%$ dijelaskan oleh variabel lain yang saat ini tidak dimasukkan ke dalam model. Persentase $R^{2}$ menunjukkan bahwa model regresi yang dihasilkan sudah baik karena model sudah memasukkan variabel biaya promosi dan jumlah sivitas yang mana merupakan dua variabel terpenting dalam program promosi ini. Ada beberapa variabel yang dapat dipertimbangkan untuk dimasukkan ke dalam model untuk memperbaiki model regresi yang ada, misalnya pelayanan (service) dan lokasi (place).

\section{III.5. Implikasi Manajerial}

Implikasi manajerial yang dapat dilakukan oleh tim program promosi IMOVSES berdasarkan penelitian ini dapat dilakukan dengan pendekatan fungsi manajerial berupa POAC (Planning, Organizing, Actuating, dan Controlling). Fungsi POAC sendiri dalam suatu organisasi adalah untuk meningkatkan efektifitas dan efisiensi suatu organisasi dalam pencapaian tujuannya (Terry 2006). Fungsi POAC akan dikaitkan dengan teori Engel (1994) yang menyatakan bahwa untuk mencapai promosi yang efektif setidaknya dipenuhi 3 kriteria, yaitu:

1. Pasar sasaran yang diharapkan

2. Hasil komunikasi yang diharapkan

3. Hasil penjualan yang diharapkan

Hasil penelitian mengenai efektivitas promosi dapat dijadikan bahan pertimbangan untuk menetapkan rencana ke depannya, mengembangkan strategi, serta mengkoordinasi aktivitas promosi selanjutnya. Proses Planning ( $p r a)$ menentukan apa yang hendak dicapai atau dilakukan, proses ini disusun berdasarkan temuantemuan pada penelitian. Proses Organizing meliputi langkah apa yang harus disusun untuk mencapai tujuan, dan siapa yang mengerjakannya. Setelah proses pengorganisasian dilakukan maka selanjutnya adalah proses Actuating, proses ini menjelaskan bagaimana pelaksanaan program atau kegiatan guna mencapai tujuan yang ditetapkan pada proses planning. Proses Controlling adalah proses post yang berarti mengontrol aktivitas yang telah dilakukan agar sesuai dengan rencana yang telah disusun. Pengendalian berarti mengawasi secara teliti setiap proses yang telah direncanakan dan memastikannya sesuai dengan yang diharapkan. 


\section{Kesimpulan}

Berdasarkan hasil penelitian, penulis dapat menarik kesimpulan bahwa berdasarkan analisis karakteristik yang dilakukan dapat disimpulkan bahwa sivitas IPB sebanyak 27 persen menggunakan produk Microsoft berlisensi dimana keputusan menggunakan produk berlisensi tersebut dipengaruhi oleh faktor usia, status sivitas, sumber dan jumlah pendapatan, seminar, serta wawasan yang dimiliki oleh sivitas IPB.

Penelitian menunjukkan respon sivitas dari segi komunikasi terhadap program promosi IMOVSES, skor EPIC Rate menunjukkan bahwa program promosi IMOVSES berada pada rentang skala cukup efektif. Analisis dengan Direct Rating Method menunjukkan bahwa program promosi IMOVSES berada pada rentang skala baik. Walaupun masuk dalam kategori promosi yang baik, tetapi skor tersebut hanya berjarak 4 nilai di atas kategori rata-rata.

Berdasarkan analisis hubungan jumlah biaya promosi dengan tingkat penggunaan produk Microsoft, maka diperoleh persamaan regresi "Jumlah pengguna produk $=27,2+0,000027$ Biaya Promosi" yang menunjukan bahwa apabila biaya promosi ditambah sebesar Rp100.000,- akan menambah jumlah pengguna (sivitas) sebanyak 3 orang. Jumlah Sivitas yang mengetahui IMOVSES namun tidak mendaftarkan diri adalah sebanyak 3.820 sivitas, maka jika variabel lain tidak berubah, dibutuhkan setidaknya biaya sebesar Rp127.300.000,- untuk menjadikan program promosi efektif secara penjualan, yakni seluruh sivitas IPB yang mengetahui program IMOVSES (14.200 sivitas) mendaftarkan diri dalam program IMOVSES.

\section{Daftar Pustaka}

Arfianto W. 2010. Analisis Faktor-Faktor yang Mempengaruhi Efektivitas Iklan pada Media Televisi. Jurnal IImu Komunikasi. 11(2): 112-136.

Engel. 1994. Perilaku Konsumen Jilid Keenam. Jakarta (ID): Binarupa Aksara.

International Data Corporation. 2012. [diunduh pada 20 Oktober 2014]. Tersedia pada http://www.internationaldata.org/cybercrime.

Ferrinadewi E. 2005. Atribut Produk yang Dipertimbangkan dalam Pembelian Kosmetik dan Pengaruhnya pada Kepuasan Konsumen di Surabaya. Jurnal Manajemen dan kewirausahaan. 7(2): 139-151.

Kotler P, Keller KL. Manajemen Pemasaran Edisi 13 Jilid 1. Jakarta (ID): Erlangga.

Kodu S. 2013. Pengaruh Harga, kualitas produk dan kualitas pelayanan terhadap keputusan pembelian mobil Toyota Avanza. Jurnal EMBA. 1(3): 1251-1259.

Mongi L, Manneke L, Repi A. Kualitas produk, strategi promosi dan harga pengaruhnya tehadap keputusan pembelian kartu simpat telkomsel di Kota Manado. Jurnal EMBA. 1(4): 2336-2346.

Patimeh I. 2010. Analisa Efektifitas Promosi Wisata pada Obyek Wisata Museum Asi Mbojo. Jurnal Pariwisata. 3(6): 431-443.

Rajab S. 2009. Analisis Faktor-Faktor yang Mempengaruhi Implementasi Perangkat Lunak Berbasis Open Source pada Perusahaan Konsultan IT. Jurnal Teknologi dan Sistem Informasi. 14(3): 78-103.

Ramdhan S. 2010. Analisis Strategi Pemasaran Produk System Online Payment Point (SOPP) Pada Kantor Pos Bogor 16000. Jurnal Ilmu Pemasaran. 7(2): 21-45. 
Sukma D. 2011. Analisis Efektivitas Promosi Above The Line dan Below The Line Sawangan Golf PT Pakuan. Jurnal Ekonomi dan Manajemen. 8(3): 124-141.

Suyanto M. 2005. Teknologi Informasi Untuk Bisnis. Yogyakarta (ID): Andi Offset. Singarimbun M, Effendi S. 1995. Metode Penelitian Survei. Jakarta (ID): LP3ES.

Tjiptono F. 2005. Strategi Pemasaran. Yogyakarta (ID): Andi Offset.

Umar H. 2005. Management Strategic in Action. Jakarta (ID): PT Gramedia Pustaka Utama.

Utami A. 2011. Analisis Strategi Promosi Online PT Pusat Media Indonesia. Jurnal IImu Pemasaran. 17(2): 114-126.

Verina E, Yulianto E, Latief W. 2014. Faktor-Faktor yang mempengaruhi keputusan pembelian pada toko fashion di jejaring sosial facebook. Jurnal Administrasi Bisnis. 10(1): 1-10. 